\title{
Normal Cell to Total Cell Ratio Measurement
}

National Cancer Institute

\section{Source}

National Cancer Institute. Normal Cell to Total Cell Ratio Measurement. NCI Thesaurus.

Code C127767.

The determination of the ratio of normal cells compared to total cells present in a sample. The measurement may be expressed as a ratio or percentage. 